\title{
The impact of Senjed (Elaeagnus angustifolia L.) peel aqueous extract on qualitative properties of cold-pressed sesame oil
}

\author{
Isa Fathollahy ${ }^{1}$ \\ ${ }^{1}$ Mamaghan branch, Islamic Azad University, Mamaghan, Iran
}

September 25, 2021

\begin{abstract}
The Senjed peel aqueous extract was added to sesame cold-pressed oil at different concentration of 0, 100, 200, 500 and 750 $\mathrm{mg} / \mathrm{kg}$ and compared with TBHQ $(200 \mathrm{mg} / \mathrm{kg})$. The Senjed peel aqueous extract showed $9.55 \pm 0.35 \%$ extraction yield, 58.17 $\pm 2.33 \%$ antioxidant activity, $573.31 \pm 3.57(\mathrm{mg} \mathrm{GAE} / 100 \mathrm{~g} \mathrm{FW})$ total phenolic content, and $151.33 \pm 2.67(\mathrm{mg} \mathrm{CAE} / 100 \mathrm{~g}$ FW) total flavonoid content. The extract preserved $59.08 \%$ of antioxidant activity after heating at 185 for 80 min. Increasing the concentration of the extract caused a significant $(\mathrm{p}<0.05)$ qualitative improvement in the oil samples. At all storage times, the highest FFA\%, peroxide and P-anisidine value belonged to oil samples containing 0 ppm of Senjed peel aqueous extract and followed by 100, 200, 500 and $750 \mathrm{ppm}$, respectively. The highest oxidative stability index was observed in oil samples containing TBHQ and $750 \mathrm{mg} / \mathrm{kg}$ concentration of extract (both $15.39 \mathrm{~h}$ ). Oil samples containing $750 \mathrm{ppm}$ of Senjed peel aqueous extract and TBHQ showed almost similar qualitative characteristics. Results showed that Senjed peel aqueous extract have antioxidant potential for stabilization of oils.
\end{abstract}

\section{Introduction}

Sensitivity to oxidation of edible oils with higher unsaturation levels changes organoleptic properties and decreases the shelf life of the oil (Abdelazim et al., 2013). One of the practical strategies that can be used to increase oil oxidative stability during processing and storage is addition of antioxidant compounds. Edible oil industries use chemicals and synthetic antioxidants in preservation of oils. However, health risks of synthetic antioxidants and society's growing demand for products that contribute to improving the quality of life has encouraged researchers to look for naturally-occurring alternatives antioxidants with comparable antioxidative properties and health benefits (Elaigwu et al., 2019; Farag et al., 2007; Iqbal \& Bhanger, 2007; Ribeiro \& Jorge, 2017). The popularity and desire to consumption of cold-pressed oils is continuously increasing among consumers. Recovery and preserving more bioactive compounds during the pressing process is the advantage of cold-pressed oils over refined oils. Lipid oxidation of oils can not only produce rancid odors, unpleasant flavors and discoloration, but can also decrease the nutritional quality and safety due to degradation products, resulting in harmful effects on human health when it is consumed (Böhm et al., 2013). In addition to fatty acid profile of oils, antioxidant polarity, structure, concentration, and mutual ratios influences oil oxidation mechanisms and rates (Choe \& Min, 2006; Sielicka et al., 2014).

The sweet smell and good taste make sesame oil a natural and desirable salad or cooking oil, especially in Asian countries. Depends on variety, genetics, environment, and ecological factors, the oil content of sesame seed from different countries has been estimated to be $50.9-55 \%$ which contains $80 \%$ unsaturated fatty acids (such as oleic acid and linoleic acid) and less than $20 \%$ of saturated fatty acids (such as palmitic and stearic acids). Sesame oil also contains significant amounts of sesamol, sesamolin, and sesamin, which have antioxidant activities (Yermanos et al., 1972; Zanjani et al., 2020). For cold-pressed oils rich in polyunsaturated fatty acids (PUFAs), the effectiveness of antioxidants is of particular importance. 
Antioxidants such as flavonoids, tannins, coumarins, curcumanoids, xanthons, phenolics, lignans and terpenoids are found in various plant parts (e.g. fruits, leaves, seeds and oils). For this reason, there is growing interest in separating these plant antioxidants and using them as natural antioxidants (Jeong et al., 2004). More than 90 species of the Senjed (Elaeagnus angustifolia L. ) are mainly distributed in subtropical regions of Asia, Europe and North America1 which are rich in terms of phytochemicals such as flavonoid compounds, sitosteroles, cardiac glycosides, terpenoids, coumarins, phenol carboxylic acids, saponins, carotenoids, vitamins, and tannins. Flavonoids which are mainly present in fruits and vegetables, due to their phenolic hydroxyl groups, are able to chelate metals, reduce lipid peroxidation and have shown a high antioxidant and free radical scavenging activities (Hamidpour et al., 2017; Saboonchian et al., 2014).

Despite studies on the antioxidant properties of various parts of Senjed fruit, literature review showed that the practical use of its extract as an antioxidant in edible oils is very limited. On the other hand, unexpectedly, the oxidative stability of sesame cold-pressed oils produced in Iran is lower (Farmani et al., 2019; Zanjani et al., 2020) than the national standard (INSO, 2016; INSO, 2013) recommendations (13 and $12 \mathrm{~h}$ for frying and blend oil, respectively). Therefore, given the presence of potentially useful bioactive compounds in Senjed and the interest in replacing synthetic antioxidants with natural ones, the main objective of this study was to evaluate the effectiveness of Senjed peel aqueous extract as a natural antioxidant at different concentration levels $(0,100,200,400$, and $600 \mathrm{ppm})$ compared to widespread synthetic antioxidant TBHQ (200 ppm), on shelf life and oxidative properties of cold-pressed sesame oil.

\section{Materials and methods}

\subsection{Materials and chemicals}

Senjed (Elaeagnus angustifolia L.) fruit obtained from the traditional market (Azarshahr, Iran) and were separated manually from the peel, then the separated peels were dried in an oven at $40{ }^{\circ} \mathrm{C}$ till the constant moisture content of $7.5 \%$. Sesame oil was freshly prepared from a traditional cold-pressed oil manufacture (Azarshahr, Iran). 1,1-Diphenyl-2-picrylhydrazyl (DPPH), gallic acid, (+) catechin 1,1,3,3,tetramethoxypropane and tert-Butylhydroquinone (TBHQ) were purchased from Sigma Chemical Co. (St. Louis, MO, USA). Folin-Ciocalteau reagent, isooctane solvent and p-anisidine reagent were purchased from E. Merck Co. (Darmstadt, Germany). All other reagents were of analytical grade.

\subsection{Preparation of Senjed peel aqueous extracts}

Using Soxhlet extractor, $20 \mathrm{~g}$ of dried and ground Senjed peel was mixed with $200 \mathrm{ml}$ of double distilled water in a round bottom flask and refluxed for about $8 \mathrm{~h}$ at $100{ }^{\circ} \mathrm{C}$. Obtained liquid extracts were separated from the solid residue by vacuum filtration, vacuum-evaporated (Heidolph Rotavapor, Germany, 40 , vacuum 0.6 bar and rpm 50) to obtain the concentrated extract. Semi-dried extracts placed in amber-colored glasses, flushed with nitrogen, and stored at 4 until the analyses.

\subsection{Determination of total phenolic content (TPC) in Senjed peel aqueous extracts}

Total phenolic compounds in the extracts were determined, using Folin-Ciocalteau reagent, by the method of Hussain et al. (2018) and expressed as $\mathrm{mg} / \mathrm{g}$ of Gallic acid equivalents (GAE) as a standard. $0.5 \mathrm{~mL}$ of extracts (at a concentration of $1-10 \mathrm{mg} / \mathrm{mL}$ extracts in water) was mixed with $2.5 \mathrm{~mL}$ of $10 \%$ FolinCiocalteu reagent and $2 \mathrm{~mL}$ of $7.5 \%$ sodium carbonate solution. After the samples were kept for $30 \mathrm{~min}$ at room temperature for incubation, the absorbance was measured at $760 \mathrm{~nm}$ in a UV/visible spectrophotometer (Ultrospec 2000; Pharmacia Biotech Ltd., Cambridge, UK).

\subsection{Determination of total flavonoid content (TFC) in Senjed peel aqueous extracts}

The spectrophotometer assay for the quantitative determination of flavonoid content was carried out as described by Chen et al. (2007). Briefly, the extract $(1 \mathrm{~mL}, 1 \mathrm{mg} / \mathrm{mL})$ was diluted with $1.25 \mathrm{~mL}$ distilled water. At zero time, $75 \mu \mathrm{L} 5 \% \mathrm{NaNO}_{2}$ were added to the mixture. After 6 min, $150 \mu \mathrm{L} 10 \% \mathrm{AlCl}_{3}$ were added. After another $5 \mathrm{~min}, 1 \mathrm{~mL} 1 \mathrm{M} \mathrm{NaOH}$ were added to the mixture. Immediately, the absorbance 
of the mixture, pink in color, was determined at $510 \mathrm{~nm}$ versus prepared water blank. Total flavonoids of extracts were expressed on a fresh weight basis as $\mathrm{mg} / 100 \mathrm{~g}$ catechin equivalents (CAE).

\subsection{Evaluation of antioxidant activity of Senjed peel aqueous extracts}

The 1, 1-diphenyl-2-picrylhydrazyl (DPPH) assay was performed according to Hussain et al. (2018). The obtained extracts and the synthetic antioxidant TBHQ $(0.1 \mathrm{~mL}$ of each) was allowed to react with $3.9 \mathrm{~mL}$ of DPPH solution $\left(6 \times 10^{-5} \mathrm{M}\right)$ and absorbance was measured at $515 \mathrm{~nm}$ after $30 \mathrm{~min}$. The DPPH scavenging percentage was calculated according to the following formula.

DPPHs Scavenging capacity $(\%)=\frac{A_{\text {control }}-A_{\text {sample }}}{A_{\text {control }}} \times 100(1)$

$\mathrm{A}=$ absorbance at $515 \mathrm{~nm}$.

\subsection{Evaluation of thermal stability of Senjed peel aqueous extracts}

Thermal stability of Senjed peel aqueous extracts was evaluated by heating at 185 in a vacuum oven (Memmert GmbH, Schwabach, Germany) for $80 \mathrm{~min}$ by $10 \mathrm{~min}$ intervals in separate crucibles. After each interval, a crucible was removed from the oven, cooled to room temperature and stored at 4 before antioxidant activity evaluation in DDPH assay system following the above-cited method.

\subsection{Qualitative properties of cold-pressed sesame oil with Senjed peel aqueous extract}

\subsubsection{Sample preparation}

Aqueous extracts of Senjed peel were added to the $100 \mathrm{~mL}$ cold-pressed sesame oil at concentrations of 0 (T0) (as negative control without antioxidant), 100 (T100), 200 (T200), 500 (T500) and 750 ppm (T750) (respectively, $0 \%, 0.01 \%, 0.02 \%, 0.05 \%$, and $0.075 \%$ of fat content). Synthetic antioxidant TBHQ was employed at their legal limit of $200 \mathrm{ppm}$ ( $0.02 \%$ of fat content) (as positive control) in cold-pressed sesame oil. All of prepared oil samples were filled in PET containers and stored at $25+-5$ and $30-35 \%$ relative humidity.

\subsubsection{Analytical procedures}

Moisture content, refractive index, iodine value (IV), and saponification value of oil samples were measured according to the AOCS Ca 2d-25, Cc 7-25, Cd 1d-92, and Cd 3-25 methods, respectively. Measurement of Peroxide value (PV), free fatty acid (FFA), and p-anisidine value (P-AV) were made after a regular interval of 15 days, following the AOCS official methods (AOCS, 2003). Total carotenoid and chlorophyll content were determined according to Jabri-Karoui \& Marzouk (2014) using a UV-Vis spectrophotometer (Pharmacia Biotech Ltd., Cambridge, UK) at 470 and $670 \mathrm{~nm}$, respectively, using the following equations:

Total chlorophyls $\left(\frac{\mathrm{mg}}{\mathrm{kg}_{\text {oil }}}\right)=\frac{A_{470 n m} \times 10^{6}}{613 \times 100 \times d}(2)$

Total carotenoids $\left(\frac{\mathrm{mg}}{\mathrm{kg}_{\mathrm{oil}}}\right)=\frac{A_{670 n \mathrm{~m}} \times 10^{6}}{2000 \times 100 \times d}(3)$

Where $\mathrm{A}$ is the maximum absorption in given wavelength, $d$ is the thickness of the cuvette $=1 \mathrm{~cm}, 613$ and 2000 is the coefficient of specific extinction in cyclohexane of pheophytin and lutein, respectively. Temperature and relative humidity of oil samples storage was $25+-5$ and $30-35 \%$., respectively.

The protein, fat, moisture, ash, crude fibre and total titrable acidity values of Senjed fruit were estimated using standard methods of analysis (AOAC, 1990). Total soluble sugar (\%) content was determined according to Cansev et al. (2011).

\subsubsection{Oxidative stability index (OSI)}

Oxidative stability index (OSI) of the oil samples determined using $2.5 \mathrm{~g}$ oil and Rancimat instrument (Model 743; Metrohm Ltd., Herisau, Switzerland) at 110 with an airflow rate of $9 \mathrm{~L} \mathrm{~h}^{-1}$ according to the AOCS Cd 12b-92 method. 


\subsection{Statistical analysis}

All experiments were performed in triplicate and data is reported as mean +- standard deviation. One-way ANOVA and Tukey's mean comparing test at $5 \%$ significance level was performed using the Minitab ver. 20.3 (Minitab, Pennsylvania, USA).

\section{Results and discussion}

\subsection{Chemical composition of Senjed (Elaeagnus angustifolia L.)}

The proximate chemical composition of Senjed (Elaeagnus angustifolia L.) fruits and cold-pressed sesame oil are presented in Table 1.

The yield of the Senjed peel aqueous extract was $9.55+-0.35 \%$. The yield of ethanolic, methanolic and aqueous sesame seed extracts was in the range of 13.37-29.48\%. Methanol had the highest yield (29.48\%), and the lowest yield was detected in water extracts (13.37\%) (Hussain et al., 2018). Percent yield of potato peels extract obtained with different organic solvents was as follow: Ethanol 10.20\%, Methanol 14.75\%, Acetone 5.88\%, Hexane 13.00\%, Petroleum ether $21.00 \%$ and Diethyl ether $15.25 \%$ (Zia-Ur-Rehman et al., 2004). Soluble sugars (47.73\%), crude fibre (21.05\%), moisture (19.48\%) and titrable acidity (7.53\%) were the most common constituents of Senjed fruit, respectively. Considering the positive correlation between the titrable acidic level with total organic acid and phenolic acid (Wang \& Fordham, 2007), Ayaz \& Bertoft (2001), reported that among determined seven phenolic acids in Elaeagnus angustifolia L., 4-hydroxybenzoic acid (45.8 mg/100 g dry wt) and cafeic acid (32 mg/100 g dry wt) were the most abundant, whereas ferulic acid $(2.3 \mathrm{mg} / 100 \mathrm{~g}$ dry wt) and benzoic acid $(11.6 \mathrm{mg} / 100 \mathrm{~g}$ dry wt) were least abundant. Crude fibre content of Senjed fruit in this study $(21.05 \%)$ was in the range of total dietary fibre content of flours from peeled and unpeeled oleaster (Elaeagnus angustifolia L.) (20.67\% to $30.65 \%$ ) that reported by Sahan et al. (2015).

The mean fat content of the Senjed fruits in this study was $0.47 \%$. Russian olive (Elaeagnus angustifolia L.) fruit samples had low fat content $(0.49 \%)$, and according to the reports of, oleic acid, linoleic acid and linolenic acid, including up to $92.8 \%$ of the fruit lipid content (Kusova \& Luk'yanchikov, 1990). An abundance of palmitoleic acid in fruit peel oil and a high amount of linoleic acid and palmitic acid in seeds oil of E. angustifolia L. was reported (Sahan et al., 2015).

The FFA\%, peroxide value, iodine value, and saponification value of the prepared cold-pressed sesame oil was $0.643 \%, 1.17 \mathrm{meq}_{\mathrm{O} 2} / \mathrm{Kg}_{\mathrm{Oil}}, 111.81\left(g_{I} / 100 g_{\mathrm{oil}}\right)$, and $193.15\left(\mathrm{mg}_{\mathrm{KOH}} / g_{\mathrm{oil}}\right)$ that was below the maximum allowable norm of Codex (Alimentarius, 1999) for cold-pressed oils. The FFA\%, peroxide value, and iodine value of the sesame seed cold-pressed oil of several African countries has been reported in the range of 0.9$1.8 \%, 0.06-6.9$ meq $\mathrm{O}_{2} / \mathrm{kg}$, and 105-117 $\left(g_{I} / 100 g_{\text {oil }}\right)$, respectively (Gharby et al., 2017; Khalid Sabahelkhier et al., 2008; Nzikou et al., 2009; Ogbonna \& Ukaan, 2013). The high iodine value of the sesame oil samples confirmed the high levels of unsaturated fatty acids (UFAs) in their fatty acid profile, which is desirable from a nutritional perspective, but makes them sensitive to autoxidation. Oil oxidative index (OSI) of coldpressed sesame oil in this study was $8.93+-0.53 \mathrm{~h}$ that was lower than national reference for frying (13 hours) and blend oils (12 hours) at the temperature of $110 \mathrm{degC}$. Assessment of oil oxidative index (OSI) in 8 cold-pressed sesame oil samples in Zanjan province of Iran showed that the induction periods was within the range of $7.53+-0.1-9.48+-0.1$ hours in the cold-pressed sesame oil samples and 18.96 +- 0.26-20.91 +-

0.01 hours in the refined samples (Zanjani et al., 2020). Farmani et al. (2019) reported that OSI of sesame oil from local extraction stores in Mazandaran province of Iran was $8.14+-1.14 \mathrm{~h}$.

\subsection{Total phenolic and flavonoid content of extracts}

The active compounds of natural sources such as phenolic and flavonoids compounds have shown to have antioxidant activities due to their ability to donate the electrons and scavenge the free radicals. Many factors such as climate, soil and ecological conditions are involved in the amount of these plants secondary metabolites (Saboonchian et al., 2014). Average TPC of aqueous extracts of the exocarp (peel) of Senjed fruit were measured as 573.31 +- $3.57 \mathrm{mg}$ GAE/100 g FW. Hassanzadeh \& Hassanpour (2018) reported 
that TPC of peel and pulp methanolic extractof Elaeagnus angustifolia L. fruits from different locations of East and West Azerbaijan provinces of Iran was in the range of $444.74-669.86$ and $423.91-561.00$ (mg GAE/100 g FW), respectively. Cansev et al. (2011) reported that average TPC of aqueous, acetone and methanolic extracts of the mesocarp and exocarp in oleaster fruit was 778.11, 558.52, 390.44; and 361.24, 413.95, 524.40 (mg GAE/100 g FW), respectively. They concluded that extraction procedures using water showed much more antioxidant capacity and total phenolic content compared to methanol and acetone extraction procedures for tested samples $(p<0.05)$.

TPC of oleaster fruits crust and crumb methanolic extracts grown in different locations of Turkey reported as in the range of 13.43-22.30 and 10.58-16.44 (mg GAE/g DM), respectively (Simsek \& Sufer, 2021). TPC in seed, flesh and peel of different genotype of oleaster methanolic extracts ranged from 2.14 to 6.26 +0.04, 0.14 to 1.54 , and 0.12 to 2.59 (mM QE/mg extract), respectively (Faramarz et al., 2015). A review of literature shows that the content of phenolic compounds in the exocarp (peel or crust) of Elaeagnus angustifolia L. fruit is higher than its mesocarp (flesh, pulp or crumb). The nature and polarity of solvent systems markedly influenced the phenolic contents of extracts. The results imply that the aqueous extract of Senjed peel could be effective in the antioxidant and free radical scavenging activity. The amount of the total phenolics of the aqueous extract of Phellodendron amurense was $70 \mu \mathrm{g} \mathrm{mg}{ }^{-1}$ (Velmurugan et al., 2018).

TFC of the extracts obtained from the peel of Senjed fruit was $151.33 \pm 2.67 \mathrm{mg}$ CAE $/ 100 \mathrm{~g} \mathrm{FW}$. Hassanzadeh \& Hassanpour (2018) reported that TFC of Elaeagnus angustifolia L. fruits peel and pulp methanolic extract in five different locations of East and West Azerbaijan provinces of Iran was in the range of $73.69-226.5$ and $94.27-209.42 \mathrm{mg} \mathrm{CAE} / 100 \mathrm{~g} \mathrm{FW}$, respectively. TFC of the methanolic extracts obtained from the crust and crumb of oleaster fruit varied between $5.99 \pm 0.45$ and $16.24 \pm 1.49 \mathrm{mg} \mathrm{CE} / \mathrm{g}$ $\mathrm{DM}$, and $3.10 \pm 0.01$ and $6.54 \pm 2.68 \mathrm{mg} \mathrm{CE} / \mathrm{g}$ DM, respectively (Simsek \& Sufer, 2021). The TFC in methanolic extracts of seed, flesh and peel of different genotype of oleaster fruit ranged from 4.7 to 17.6, 0.62 to $1.90,0.64$ to 1.13 (mM QE/mg extract), respectively (Faramarz et al., 2015). TFC of the extracts obtained from the crust and crumb of oleaster fruit varied between 5.99 to 16.24 , and 3.10 and 6.54 (mg CE/g DM), respectively (Simsek \& Sufer, 2021).

After 24 days of storage, the trolox equivalent (TE) of soybean and cottonseed oils fortified with $400 \mathrm{mg} / \mathrm{kg}$ rosemary extract was significantly higher than the TE of oils fortified with $200 \mathrm{mg} / \mathrm{kg}$ of the synthetic antioxidants BHA and BHT (Yang et al., 2016).

\subsection{Antioxidant activity of Senjed peel aqueous extracts}

The free radical (DPPH) scavenging activity (\%) of aqueous extracts obtained from exocarp (peel) of Senjed (Elaeagnus angustifoliaL.) fruits was $58.17 \%$. The free radical (DPPH) scavenging activity DPPH of aqueous, acetone and methanolic extracts of the mesocarp and exocarp in oleaster fruit are measured as 28.03, 27.16, 27.82; and 27.62, 27.95, 27.84 ( $\mu \mathrm{mol}$ Trolox/g FW), respectively ((Cansev et al., 2011). In the study of Hassanzadeh \& Hassanpour (2018), the mean antioxidant capacity of peel and pulp extracts obtained by $85 \%$ methanol based on the DPPH assay was 74.71 and $53.76 \%$, respectively. According to Faramarz et al. (2015), the mean antioxidant capacity of peel, pulp and seed based on the DPPH assay in different genotype of E. angustifolia L. was 86.95, 91.78 and 35.83\%, respectively. Also, according to Incilay (2014), the antioxidant capacity for leaf, flower, peel and fruit of E. angustifolia L. fruit was 1.036, 1.65, 1.28 and $2.51 \mu \mathrm{g}$ trolox/g, respectively.

Velmurugan et al. (2018) reported that the aqueous extract of $P$. amurense possesses good DPPH scavenging activity. When compared to the positive control of L-ascorbic acid it has less activity but there is little difference at a concentration of $500 \mu \mathrm{g}$. DPPH activity results reveal that the Senjed peel aqueous extract possesses hydrogen donating ability and, may act as primary antioxidants. The effectiveness of antioxidant activity depends on the inhibition reaction between a peroxyl radical and the antioxidant. The electronattractive inductive effect of the alpha carbonyl group in the para position should in fact destabilize the phenoxyl radical and reduce the radical scavenging ability of compounds (Kajiyama \& Ohkatsu, 2001). The following possible mechanism can be applied for DPPH radical scavenging activity. The dimer formation 
during the reaction between two phenoxyl radicals can influence the antioxidant property of the extract. These dimers may initially reduce DPPH radical scavenging (Bortolomeazzi et al., 2007).

\subsection{Thermal stability of Senjed peel aqueous extracts}

Effect of heating (at 185 ) on thermal stability of Senjed peel aqueous extracts for different intervals is shown in Fig. 1. Up to 30 min heating time, extracts were almost stable, but after 40 min a gradual decrease in antioxidant activity was observed with the increase in heating period. The decrease in antioxidant activity was not significant $(p<0.05)$ up to $40 \mathrm{~min}$ but became pronounced after 50 min heating time. At the 80 min heating interval, extracts exhibited $34.37 \%$ antioxidant activity ( $59.08 \%$ remaining antioxidant activity). Iqbal \& Bhanger (2007) reported that the decrease in antioxidant activity methanolic extracts of garlic was not significant $(p<0.05)$ up to $40 \mathrm{~min}$ but became pronounced after 50 min heating time at 185 . The stability of some phenolic antioxidants against thermal oxidation was reported by Hamama \& Nawar (1991) as follow: BHT > PG > BHA > TBHQ after 60 min heating at 185 . Comparing the results, it is observed that the thermal stability of Senjed peel aqueous extracts is higher than synthetic antioxidants. Liu et al. (2016) reported that as heating temperature and heating time increased, losses of TBHQ in palm oil increased due to increasing volatility of TBHQ. Losses of antioxidant activity, after longer heating times at high temperatures, may be due to vaporization and volatility, and various chemical reactions occurring during oxidation, leading to the formation of hydroperoxides, hydrolysis, polymerization, chemical decomposition, which lead to deterioration in oils and fats giving rancidity (Liu et al., 2016; Warner \& Knowlton, 1997). These results reveal that Senjed peel aqueous extracts is a potential source of natural antioxidants, which is applicable in food systems even at high processing temperatures.

\subsection{Qualitative properties of cold-pressed sesame oil with Senjed peel aqueous extract}

\subsubsection{Free fatty acids (FFA)}

Free fatty acids (FFA) are the main products of oil hydrolytic, enzymatic and thermal hydrolysis that considered as an important marker to measure the rancidity and oxidative deterioration of the food/lipids. In addition to treatment, the effect of storage time on FFA\% was also significant $(p<0.05)$ as the value of FFA\% increased as the storage period increased. Except for day 0 of storage, on the 15 th, 30th and 45th day, there was significant difference between the treatments in terms of FFA $\%(p<0.05)$. The FFA\% decreased as the concentration of extract was increased. The highest FFA\% contents $(5.21 \%)$ were observed in control group (T0) $(p<0.05)$ on the 45th day while T750 and TTBHQ showed the lowest FFA contents $(2.81 \%$ and $2.73 \%$, respectively) on the same day of storage. Totally, except T0, FFAs content in cold-pressed sesame oil treatments was lower than Codex Alimentarius standards (Alimentarius, 1999) (Acid value: $4.0 \mathrm{mg} \mathrm{KOH} / \mathrm{g}$ Oil). These results signify anti-oxidation activity of the Senjed peel aqueous extract.

Results of treatments (Fig. 2), revealed that T750 had better effect on reduction of FFA contents (e.g. $0.91,1.72$ and $2.81 \%$ on day 15,30 and 45$)$ comparing to the FFA\% values of the positive reference group (TTBHQ) $(0.75,1.35$ and $2.73 \%$ on day 10,20 and 30$)$ respectively.

Totally, except T0, FFAs content in cold-pressed sesame oil treatments was lower than Codex Alimentarius standards (Acid value: $4.0 \mathrm{mg} \mathrm{KOH} / \mathrm{g}$ Oil), so we deduced that Senjed peel aqueous extract as a potential natural active ingredient, can improve the shelf life of oils and fats. Previously, Hussain et al. (2018); Iqbal \& Bhanger (2007); Elaigwu et al. (2019), Jung et al. (2021), and Shahid et al. (2018) also claimed that antioxidant activity of sesame seed extracts, garlic extracts, leaf extracts of Neem, rosemary and garlic, and cinnamon extract exhibited the comparable reduction effect on FFA contents in different oil as compared with synthetic antioxidant.

\subsubsection{Peroxide value (PV)}

The PV measurement is a good indicator for the evaluation of oil quality in the initial stage of oil oxidation process (Hussain et al., 2018). By increasing the storage time, a gradual increase in peroxide value of all samples was observed (Fig. 2). At all stages, highest PV was observed for negative control sample (T0) followed by T100, T200, T500 and T750 respectively. Senjed peel aqueous extract at all concentrations 
decreased the peroxide value of the cold-pressed sesame oil which concluded the good antioxidant and stabilizing ability. A regular increase in PV as a function of storage time was observed for all the samples at all intervals, but this increase was very slow for stabilized samples with Senjed peel aqueous extracts. PV of TTBHQ was lower than T750 initially; but became almost equal at the 45th day of storage. Generally, change in peroxide values

were in a concentration-dependent manner and the values for all samples correspond to normal Codex values (Alimentarius, 1999), which recommended a maximum PV of 15 meq $\mathrm{O}_{2} \mathrm{~kg}^{-1}$. A pattern similar to the results of our study was also observed by Hussain et al. (2018) and Iqbal \& Bhanger (2007) that studied the effect of methanolic extract of sesame seed and garlic extracts on the stability of sunflower oil. They suggested that sesame seed extracts $(1000 \mu \mathrm{L} / 100 \mathrm{ml}$ oil $)$ and garlic extract (1000 ppm) can be considered as BHT alternative.

\subsection{3. $\mathrm{P}$-anisidine value $(\mathrm{P}-\mathrm{AV})$}

$\mathrm{P}$-anisidine value measures the secondary oxidation product of the oil and is important to check the oxidative quality of fats and oils. P-anisidine value for all the samples were determined up to 45 days of storage (Fig. 3). The results indicated that the use of Senjed peel aqueous extract resulted in significant inhibition of P-anisidine value. The negative control group (T0) exhibited the highest P-anisidine value (i.e. 2.98, 6.31 and 9.51 on 15,30 and 45 th day of storage) whereas the least P-anisidine value (i.e. $1.23,2.55$ and 3.11 on 15,30 and 30th day of storage) were observed with positive control group TTBHQ. It is observed that the P-anisidine value increased slightly but steadily as storage time extended and indicated that Panisidine value reduced as the concentration of extracts increased. According to Elaigwu et al. (2019), an acceptable P-anisidine value for well-refined oils is between 1 and $10 \mathrm{mmol} \mathrm{kg}^{-1}$, whereas oils with high levels of polyunsaturated fatty acids might have higher levels even when fresh. Comparing the antioxidant potential of the positive control group (TTBHQ) with all treatments, T750 group represented the lowest P-anisidine value which was close to the TTBHQ group. Thus, Senjed peel aqueous extracts could be considered as a good natural antioxidants to stabilize the cold-pressed sesame oil.

\subsubsection{Oxidative stability index (OSI)}

The results showing the effect of Senjed peel aqueous extract compared to positive control (TBHQ) and negative control (T0) samples on the oxidative stability of cold-pressed sesame oil are presented in Fig. 4. There was statistically significant differences between different treatments $(p<0.05)$. As expected, samples without the addition of any antioxidants (T0) were oxidized easily, and indicated the lowest OSI values $(9.05 \mathrm{~h})$. In contrast, samples containing synthetic antioxidants (TTBHQ) and the highest concentration of extract (T750) showed the highest index of oxidative stability index (both $15.39 \mathrm{~h}$ ). As can be seen, with increasing the concentration of the extract, the oxidative stability of the oil samples increases and at a concentration of $750 \mathrm{ppm}$, it is equivalent to a sample containing synthetic antioxidant TBHQ. Except T100 treatment, the OSI values of oils with added Senjed peel aqueous extract or synthetic antioxidants were found to be significantly larger $(p<0.05)$ than that of the negative control oils (T0). Incorporation of soybean, cottonseed and rice bran oils with rosemary extract resulted significantly $(p<0.05)$ higher OSI values than that of oil with added synthetic antioxidant (BHA + BHT) (Yang et al., 2016).

\section{Conclusion}

From the present study, it was concluded that Senjed peel aqueous extract can stabilize cold-pressed sesame oil effectively at a concentration of $750 \mathrm{ppm}$. It inhibits the thermal deterioration of oil by improving its hydrolytic stability, inhibit the lipid oxidation and reduce the loss of polyunsaturated fatty acids (PUFAs). Senjed peel aqueous extract at concentration of $750 \mathrm{ppm}$ has stabilization efficacy comparable to the common synthetic antioxidant TBHQ at its legal limit. Therefore, Senjed peel aqueous extract can be recommended as the potent source of natural antioxidant for the stabilization of food and food product, especially edible vegetable oils rich in unsaturated fatty acids.

\section{Formatting of funding sources}


This research did not receive any specific grant from funding agencies in the public, commercial, or not-forprofit sectors.

\section{References}

Abdelazim AA, Mahmoud A, Ramadan-Hassanien MF (2013) Oxidative stability of vegetable oils as affected by sesame extracts during accelerated oxidative storage. J Food Sci Technol 50:868-878. https://doi.org/10.1007/s13197-011-0419-8

Elaigwu ED, Ogo OA, Esien EE, Godwin OO (2019) Effects of Ethanolic Leaf Extracts of Neem (Azadirachta indica) on Oxidative Stability of Palm Oil. Res J Phytochem 13:1-10. https://doi.org/10.3923/rjphyto.2019.1.10

Farag RS, Mahmoud EA, Basuny AM (2007) Use crude olive leaf juice as a natural antioxidant for the stability of sunflower oil during heating. Int J Food Sci Technol 42:107-115. https://doi.org/10.1111/j.13652621.2006.01374.x

Iqbal S, Bhanger MI (2007) Stabilization of sunflower oil by garlic extract during accelerated storage. Food Chem 100:246-254. https://doi.org/10.1016/j.foodchem.2005.09.049

Ribeiro EF, Jorge N (2017) Oxidative stability of soybean oil added to coffee husk extract (Coffea arabica l.) under accelerated storage conditions. Food Sci Technol 37:5-10. https://doi.org/10.1590/1678-457X.06117

Böhm T, Berger H, Nejabat M, et al (2013) Food-derived peroxidized fatty acids may trigger hepatic inflammation: A novel hypothesis to explain steatohepatitis. J Hepatol 59:563-570. https://doi.org/10.1016/j.jhep.2013.04.025

Choe E, Min DB (2006) Mechanisms and factors for edible oil oxidation. Compr Rev Food Sci Food Saf 5:169-186. https://doi.org/10.1111/j.1541-4337.2006.00009.x

Sielicka M, Malecka M, Purlan M (2014) Comparison of the antioxidant capacity of lipid-soluble compounds in selected cold-pressed oils using photochemiluminescence assay (PCL) and DPPH method. Eur J Lipid Sci Technol 116:388-394. https://doi.org/10.1002/ejlt.201300356

Yermanos DM, Hemstreet S, Saleeb W, Huszar CK (1972) Oil content and composition of the seed in the world collection of sesame introductions. J Am Oil Chem Soc 49:20-23. https://doi.org/10.1007/BF02545131

Zanjani D, Afshar G, Milani A, et al (2020) Evaluation of the Composition and Oxidative Stability of Coldpressed Sesame Oils in the Market of Zanjan Province, Iran (2019). J Human, Environ Heal Promot 6:159-66. https://doi.org/10.29252/jhehp.6.4.2

Jeong S-M, Kim S-Y, Kim D-R, et al (2004) Effect of Seed Roasting Conditions on the Antioxidant Activity of Defatted Sesame Meal Extracts. J Food Sci 69:C377-C381. https://doi.org/https://doi.org/10.1111/j.13652621.2004.tb10701.x

Okmen G, Turkcan O (2014) Okmen and Turkcan Afr J Tradit Complement Altern Med . (2014) 11 ( 1 ): 116-120. 11:116-120

Saboonchian F, Jamei R, Hosseini Sarghein S (2014) Phenolic and flavonoid content of Elaeagnus angustifolia L. (leaf and flower). Avicenna J phytomedicine 4:231-8. https://doi.org/10.22038/ajp.2014.1975

Hamidpour R, Hamidpour S, Hamidpour M, et al (2017) Russian olive (Elaeagnus angustifolia L.): From a variety of traditional medicinal applications to its novel roles as active antioxidant, anti-inflammatory, anti-mutagenic and analgesic agent. J Tradit Complement Med 7:24-29. https://doi.org/10.1016/j.jtcme.2015.09.004

Farmani J, Tirgarian B, Razmpour M (2019) Evaluation of physicochemical properties of sesame oil from local extraction stores of Mazandaran province. Food Sci Technol 15:175-187 
INSO 4152 (2016) Edible Fats \& Oils - Frying oil - Specifications and Test Methods (Iranian National Standardization Organization. 2nd. Revision, 2016)

INSO 5950 (2013) Blend oil- Specifications (Iranian National Standardization Organization. 1st. revision, 2013).

Hussain SA, Hameed A, Ajmal I, et al (2018) Effects of sesame seed extract as a natural antioxidant on the oxidative stability of sunflower oil. J Food Sci Technol 55:4099-4110. https://doi.org/10.1007/s13197-018$3336-2$

Chen HY, Lin YC, Hsieh CL (2007) Evaluation of antioxidant activity of aqueous extract of some selected nutraceutical herbs. Food Chem 104:1418-1424. https://doi.org/10.1016/j.foodchem.2007.02.004

Jabri-Karoui I, Marzouk B (2014) Bioactive Compounds, Antioxidant Activities and Heat Stability of Corn Oil Enriched with Tunisian Citrus aurantium L. Peel Extract. J Am Oil Chem Soc 2014 918 91:1367-1375. https://doi.org/10.1007/S11746-014-2485-3

AOAC (1990) Official Methods of Analysis of Association of Official Analytical Chemists. Washingt DC, USA

Cansev A, Sahan Y, Celik G, et al (2011) Chemical Properties and Antioxidant Capacity of Elaeagnus angustifolia L. Fruits. Asian J Chem 23:2661-2665

Zia-Ur-Rehman, Habib F, Shah WH (2004) Utilization of potato peels extract as a natural antioxidant in soy bean oil. Food Chem 85:215-220. https://doi.org/10.1016/j.foodchem.2003.06.015

Wang SY, Fordham IM (2007) Differences in chemical composition and antioxidant capacity among different genotypes of autumn olive (Elaeagnus umbellate Thunb.). Food Technol Biotechnol 45:402-409

Ayaz FA, Bertoft E (2001) Sugar and phenolic acid composition of stored commercial oleaster fruits. J Food Compos Anal 14:505-511. https://doi.org/10.1006/jfca.2001.1004

Sahan Y, Gocmen D, Cansev A, et al (2015) Chemical and techno-functional properties of flours from peeled and unpeeled oleaster (Elaeagnus angustifolia L.). J Appl Bot Food Qual 88:34-41. https://doi.org/10.5073/JABFQ.2015.088.007

Kusova RD, Luk'yanchikov MS (1990) Fatty acid composition of the fruit oil of Elaeagnus angustifolia. Chem Nat Compd 25:718. https://doi.org/10.1007/BF00598274

Alimentarius C (1999) Codex standard for named vegetable oils. Codex Stand 210:1-13

Gharby S, Harhar H, Bouzoubaa Z, et al (2017) Chemical characterization and oxidative stability of seeds and oil of sesame grown in Morocco. J Saudi Soc Agric Sci 16:105-111. https://doi.org/10.1016/j.jssas.2015.03.004

Nzikou JM, Matos L, Bouanga-Kalou G, et al (2009) Chemical composition on the seeds and oil of Sesame (Sesamum indicum L.) grown in Congo-Brazzaville. Adv J Food Sci Technol 1:6-11

Ogbonna P, Ukaan S (2013) Chemical composition and oil quality of seeds of sesame accessions grown in the Nsukka plains of South Eastern Nigeria. African J Agric Res 8:797-803. https://doi.org/10.5897/AJAR12.1702

Khalid Sabahelkhier M, Elgasim A, Yagoub A, et al (2008) Chemical Composition and Oil Characteristics of Sesame Seed Cultivars Grown in Sudan. Res J Agric Biol Sci 4:761-766

Farmani J, Tirgarian B, Razmpour M (2019) Evaluation of physicochemical properties of sesame oil from local extraction stores of Mazandaran province. Food Sci Technol 15:175-187

Hassanzadeh Z, Hassanpour H (2018) Evaluation of physicochemical characteristics and antioxidant properties of Elaeagnus angustifolia L. Sci Hortic (Amsterdam) 238:83-90. https://doi.org/10.1016/j.scienta.2018.04.041 
Simsek M, Sufer Ö (2021) Physical, Bioactive and Textural Properties of Oleaster (Elaeagnus angustifolia L.) Fruit from Different Locations in Turkey. Turkish J Agric - Food Sci Technol 9:723-727. https://doi.org/10.24925/turjaf.v9i4.723-727.4025

Faramarz S, Dehghan G, Jahanban-Esfahlan A (2015) Antioxidants in different parts of oleaster as a function of genotype. BioImpacts 5:79-85. https://doi.org/10.15171/bi.2015.09

Velmurugan N, Kalpana D, Cho JY, Lee YS (2018) Chemical composition and antioxidant capacity of the aqueous extract of Phellodendron amurense. J For Res 29:1041-1048. https://doi.org/10.1007/s11676-017$0532-2$

Yang Y, Song X, Sui X, et al (2016) Rosemary extract can be used as a synthetic antioxidant to improve vegetable oil oxidative stability. Ind Crops Prod 80:141-147. https://doi.org/10.1016/j.indcrop.2015.11.044

Incilay G (2014) Volatile Composition, Antimicrobial and Antioxidant Properties of Different Parts from Elaeagnus angustifolia L. J Essent Oil-Bearing Plants 17:1187-1202. https://doi.org/10.1080/0972060X.2014.929044

Kajiyama T, Ohkatsu Y (2001) Effect of para-substituents of phenolic antioxidants. Polym Degrad Stab 71:445-452. https://doi.org/10.1016/S0141-3910(00)00196-8

Bortolomeazzi R, Sebastianutto N, Toniolo R, Pizzariello A (2007) Comparative evaluation of the antioxidant capacity of smoke flavouring phenols by crocin bleaching inhibition, DPPH radical scavenging and oxidation potential. Food Chem 100:1481-1489. https://doi.org/10.1016/j.foodchem.2005.11.039

Hamama AA, Nawar WW (1991) Thermal Decomposition of Some Phenolic Antioxidants. J Agric Food Chem 39:1063-1069. https://doi.org/10.1021/jf00006a012

Liu C, Li J, Bi Y, et al (2016) Thermal losses of tertiary butylhydroquinone (TBHQ) and its effect on the qualities of palm oil. J Oleo Sci 65:739-748. https://doi.org/10.5650/jos.ess16041

Warner K, Knowlton S (1997) Frying quality and oxidative stability of high-oleic corn oils. J Am Oil Chem Soc 74:1317-1322

Jung H, Kim I, Jung S, Lee J (2021) Oxidative stability of chia seed oil and flax seed oil and impact of rosemary (Rosmarinus officinalis L.) and garlic (Allium cepa L.) extracts on the prevention of lipid oxidation. Appl. Biol. Chem. 64

Shahid MZ, Saima H, Yasmin A, et al (2018) Antioxidant capacity of cinnamon extract for palm oil stability. Lipids Health Dis 17:1-8. https://doi.org/10.1186/s12944-018-0756-y

Table 1. Chemical composition of Senjed (Elaeagnus angustifolia L.) fruit and cold-pressed sesame oil.

\begin{tabular}{llll}
\hline Cold-pressed sesame oil & Cold-pressed sesame oil & Senjed (Elaeagnus angustifolia L.) fruit & Senjed (Elaeagnus \\
\hline Moisture and volatile matter $(\%)$ & $0.27 \pm 0.03$ & Protein $(\%)$ & $4.69 \pm 0.85$ \\
Refractive index $(25)$ & $1.465 \pm 0.001$ & Fat $(\%)$ & $0.49 \pm 0.01$ \\
Iodine value $\left(g_{I} / 100 g_{\text {oil }}\right)$ & $111.81 \pm 1.57$ & Moisture $(\%)$ & $19.48 \pm 0.17$ \\
Saponification value $\left(\mathrm{mg}_{\mathrm{KOH}} / g_{\text {oil }}\right)$ & $193.15 \pm 2.65$ & Ash $(\%)$ & $1.22 \pm 0.02$ \\
OSI $(h)$ & $8.93 \pm 0.54$ & Crude fibre $(\%)$ & $21.05 \pm 0.17$ \\
FFA $(\%$, Oleic acid) & $0.643 \pm 0.02$ & Total titratable acidity $(\%)$ & $7.53 \pm 0.37$ \\
PV (meq $\left./ \mathrm{Kg}_{\text {Oil }}\right)$ & $1.17 \pm 0.03$ & Total soluble sugar $(\%)$ & $47.73 \pm 4.37$ \\
p-AV & $0.85 \pm 0.01$ & Yield of peel extract $(\%)$ & $9.55 \pm 0.35$ \\
Total chlorophylls $\left(\mathrm{mg} / \mathrm{Kg}_{\mathrm{Oil}}\right)$ & $1.715 \pm 0.001$ & & \\
Total carotenoids $\left(\mathrm{mg} / \mathrm{Kg}_{\text {Oil }}\right)$ & $43.51 \pm 0.129$ & & \\
\hline
\end{tabular}

Data are mean \pm SD of three replications. 
Table 2. Total phenolic, flavonoid and antioxidant activities of Senjed peel (Elaeagnus angustifolia L.) aqueous extract.

Total phenolic content (TPC) (mg Total flavonoid content (TFC)

GAE/100 g FW) (mg CAE/100 g FW) DPPH scavenging (\%)

$\begin{array}{lll}573.31 \pm 3.57 & 151.33 \pm 2.67 & 58.17 \pm 2.33\end{array}$

GAE: Gallic acid equivalent, CAE: Catechin equivalent, FW: fresh weight.

Figure legends

Figure 1. Effect of heating treatment (185 ) on antioxidant activity of Senjed peel aqueous extracts as a function of heating time. Mean values followed by the same superscript letters are not significantly different $(\mathrm{p}>0.05)$. Data are mean + - standard deviation $(\mathrm{n}=3)$.

Figure 2. Effect of different concentrations of Senjed peel extracts on free fatty acid (\%FFA) content of cold-pressed sesame oil.

Figure 3. Effect of different concentrations of Senjed peel aqueous extracts on peroxide value of cold-pressed sesame oil.

Figure 4. Effect of different concentrations of Senjed peel aqueous extracts on P-anisidine value of coldpressed sesame oil.

Figure 5. Effect of different concentrations of Senjed peel aqueous extracts on oxidative stability index (OSI) of cold-pressed sesame oil. Mean values followed by the same superscript letters are not significantly different $(\mathrm{p}>0.05)$.

\section{Hosted file}

Figures.docx available at https://authorea.com/users/436930/articles/538921-the-impact-ofsenjed-elaeagnus-angustifolia-l-peel-aqueous-extract-on-qualitative-properties-of-coldpressed-sesame-oil 